\title{
Changes in Proopiomelanocortin Primary Transcript Levels in the Anterior Pituitary Accompany Increased Adrenocorticotropin Secretion During the Diurnal Surge
}

\author{
Seung P. Kwak, Elizabeth A. Young, Huda Akil and Stanley J. Watson \\ Mental Health Research Institute, University of Michigan, Ann Arbor, Michigan 48109, USA. \\ Key words: proopiomelanocortin, transcription, diurnal rhythm, messenger ribonucleic acid regulation.
}

\begin{abstract}
Proopiomelanocortin (POMC) gene transcription in the anterior pituitary varies during stress and glucocorticoid feedback. These changes appear to parallel alterations in peptide release. The diurnal rhythm of the hypothalamo-pituitary-adrenal axis also involves the periodic excursion of adrenocorticotropin (ACTH) levels in plasma, but it is not clear whether the diurnal release is accompanied by changes at the transcriptional level. In the present study, we have initially characterized the heteronuclear species of POMC (hnPOMC) RNA found in the anterior pituitary by a Northern blot analysis and subsequently used this method to quantitate relative changes in the levels of heteronuclear transcript during diurnal stimulation. Two species of RNA migrating at $6.0 \mathrm{~kb}$ and $4.1 \mathrm{~kb}$ were found in the nuclear fraction of the anterior pituitary. Successive probing by various POMC cRNAs indicated that the $6.0 \mathrm{~kb}$ fragment was the primary transcript and the $4.1 \mathrm{~kb}$ fragment corresponded to the intron A-containing processing intermediate of POMC.

The nuclear species were quantitated after acute swim stress and during the diurnal ACTH secretion. Acute swim increased plasma ACTH levels by $243 \%$ after $30 \mathrm{~min}$. This was paralleled by a $214 \%$ increase in the primary transcript RNA levels. Endogenous circadian stimulation in the evening produced a smaller rise of plasma ACTH (79\%), and was accompanied by a $34 \%$ increase in POMC hnRNA levels. Nuclear processing intermediate $(4.1 \mathrm{~kb})$ and the mRNA levels did not vary during the evening. These results suggest that the diurnal mechanism transiently increases ACTH release as well as POMC gene transcription in the anterior pituitary. Release and transcription appear to be tightly coupled during circadian activation as well as during stress.
\end{abstract}

The release of adrenocorticotropin (ACTH) from the anterior pituitary corticotropes is stimulated during various physiological conditions. Stress activates a brain mechanism that stimulates the release of ACTH (1-3). A diurnal rhythm of the hypothalamopituitary-adrenal (HPA) axis also exists in many mammals with the peak of ACTH secretion occurring at the subjective morning $(4,5)$. Thus, in nocturnal animals such as rats, the peak period occurs at the onset of the dark phase. Hypothalamic ACTH secretagogues, namely corticotropin-releasing hormone (CRH) and arginine vasopressin (AVP), appear to function as a final common pathway to transmit the secretory information generated by stress and the diurnal drive. CRH appears to be the predominant secretagogue in rats, with AVP having a significant potentiating effect on $\mathrm{CRH}$-induced $\mathrm{ACTH}$ release. In addition to the stimulatory regulators of ACTH release, adrenal glucocorticoids which are liberated by ACTH function as an inhibitory signal on ACTH secretion. Apparently, feedback inhibition by glucocorticoids can occur via various possible brain sites (6-12).

Altered release of ACTH produced by these regulatory factors has often been associated with changes in proopiomelanocortin (POMC) biosynthesis in the pituitary corticotropes, particularly at the level of gene transcription (13-15). For instance, transcription increases $15 \mathrm{~min}$ after $\mathrm{CRH}$ stimulation in vitro and reflects the changes in ACTH release (15). Similarly, dexamethasone inhibition of ACTH release in vivo reduces transcription rates within $30 \mathrm{~min}(13,15)$. Quantitation of primary transcript (hnRNA) species by $\mathrm{S} 1$ nuclease or RNase protection assays has yielded results which are consistent with those obtained from transcription rate analysis $(16,17)$. The close relationship found between hnRNA levels and transcriptional activity suggests that the primary transcript has an extremely short half-life and that quantitation of primary transcripts can be used to estimate the effects of various physiological stimuli on gene transcription. Using a steady-state hnRNA analysis, Levin et al. (17) have demonstrated that $\mathrm{CRH}$-induced ACTH release in vitro is accompanied by increased levels of POMC primary transcript. In contrast, AVP effects on the anterior pituitary were found to be primarily on secretion with possible inhibitory effects on CRH- 
stimulated POMC hnRNA levels. Thus, the existing evidence suggests that $\mathrm{ACTH}$ release induced by $\mathrm{CRH}$ is accompanied by changes in POMC gene transcription both in vitro and in vivo.

The structure of the POMC gene has been elucidated previously (18). The rat POMC gene contains 2 introns (Fig. 1). Intron A spans $3.0 \mathrm{~kb}$ and is thought to contain a middle repetitive element near the exon 2 border, while intron $\mathrm{B}$ is approximately $1.8 \mathrm{~kb}$ long. An alternative splice site exists at the intron A-exon 2 border and yields two species of mature RNA (differing in the existence or absence of 30 nucleotides (nts) upstream of exon 2) in the pituitary. The primary transcript transcribed from this gene contains both introns $\mathrm{A}$ and $\mathrm{B}$ that must be spliced out to produce a mature messenger RNA. The introns may be sequentially excised via two pathways (i.e. intron A spliced first, then B, or intron B spliced first, then A). Each pathway produces a different processing intermediate species (see Fig. 1). Data from nuclease protection studies (17) suggest that the processing occurs predominantly by the formation of intron A-containing intermediates (wider arrows in Fig. 1).

The diurnal secretion of ACTH from the anterior pituitary differs in various aspects from the type of release normally observed after stress. Changes in ACTH are small during diurnal drive ( $\sim 100 \%$ increase compared to basal AM levels) and occur over long periods such that increased levels persist for 2 to $3 \mathrm{~h}$. Studies have shown that diurnal ACTH secretion occurs in a pulsatile fashion $(4,19)$ like many other anterior pituitary hormones. The summation of the elevated ultradian peaks (which occur approximately every $20 \mathrm{~min}$ ) appears to constitute the evening elevation (19). In contrast, the secretory changes observed after stress are abrupt. A rapid increase in ACTH release occurs in plasma within 2 to 3 min of stress onset. Levels decline towards baseline soon afterwards and appear to involve glucocorticoid feedback. While CRH has been implicated in both types of ACTH release, the manner by which $\mathrm{CRH}$ neurons are stimulated may be different. Furthermore, the degree of synergism found between AVP and CRH may differ between stress and circadian conditions. Given these differences, it is not clear whether the peak diurnal ACTH secretion is accompanied by an increase in POMC expression. Our previous results have shown that there are no detectable changes in $\beta$-endorphin or POMC mRNA content in the anterior pituitary during the diurnal cycle (20). Since these two measures are relatively insensitive to transient changes in gene expression, in the present study, we attempted to determine whether the diurnal ACTH release is accompanied by similar changes in POMC hnRNA content. We developed a Northern blot assay with adequate sensitivity to detect heteronuclear species from individual anterior pituitaries. Using this assay, we quantitated POMC hnRNA levels to approximate the effects of transient endogenous stimuli on gene transcription.

\section{Results}

For the initial characterization of POMC hnRNA species, $5 \mu \mathrm{g}$ of poly-A RNA from the anterior pituitary was blotted, then probed successively with intron $A$, intron $B$, exon $1-2$, and exon 3 cRNAs. Two bands migrating at $6.0 \mathrm{~kb}$ and at $4.1 \mathrm{~kb}$ (bands

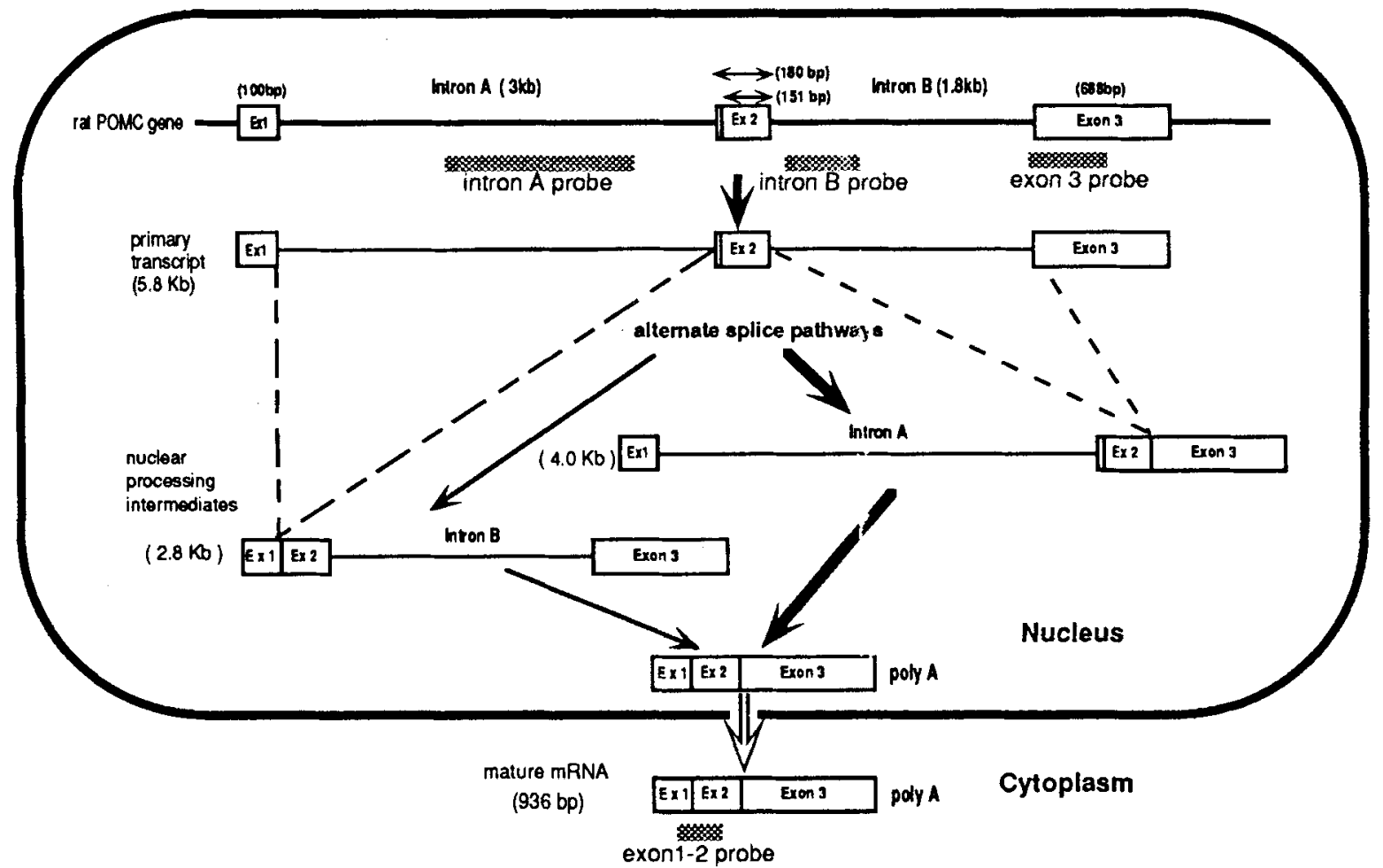

FIG. 1. Transcription and post-transcriptional processing of POMC (adapted from Levin et al. (17)). The lengths of the primary transcript, two possible forms of the processing intermediate, and the mature mRNA are indicated in parentheses. Arrows represent processing pathways, thicker being more predominant. Probes are denoted by hatched bars (genomic clones are drawn against the POMC gene, cDNA cloned from PCR against the POMC mRNA). Intron A probe: BamHI-KpnI gene fragment ( $1.5 \mathrm{~kb}$ ); intron B probe: AccI-XbaI gene fragment $(0.4 \mathrm{~kb})$; exon 3 probe: $0.39 \mathrm{~kb}$ Alul gene fragment containing $350 \mathrm{bp}$ of exon 3; exons 1-2 probe: $150 \mathrm{bp}$ cDNA from PCR containing 32 bp of exon 1 and 118 bp of exon 2. 
$A$ and $B$, respectively) were detected by an intron A probe (lane 1, Fig. 2A). The sizes of these bands were extrapolated using the RNA ladder (BRL) as size markers. These bands matched the predicted lengths of the primary transcript $(5.8 \mathrm{~kb})$ and the intron A-containing intermediate species $(4.0 \mathrm{~kb})$ of POMC. Probes complementary to various portions of the POMC gene were subsequently used to characterize band $A$ as the primary transcript species of POMC. The $6.0 \mathrm{~kb}$ band was visible after probing by the intron $B$ probe (lane 2, Fig. 2A). Re-probing the membrane with the cRNA spanning exons 1 and 2 faintly revealed bands $\mathrm{A}$ and $\mathrm{B}$, and intensely hybridized to the $1.0 \mathrm{~kb} \mathrm{mRNA}$ band (not shown). Similar results were obtained from probing by an exon 3 cRNA (lane 3, Fig. 2A). Extraneous fragments were periodically seen but were inconsistent with the size predicted for the heteronuclear transcripts or did not hybridize consistently to all POMC probes and were therefore discounted as unlikely candidates for the heteronuclear transcript. The control blots containing poly-A RNA ( $5 \mu \mathrm{g})$ from the hippocampus remained clean after probing by exon 3 cRNA (lane 4 , Fig. 2A).

To determine whether bands $A$ and $B$ represent the nuclear POMC transcripts, three anterior pituitaries were pooled for nuclear fractionation. Bands $\mathbf{A}$ and $\mathbf{B}$ were localized in the nuclear but not in the cytoplasmic fraction (Fig. 2B). These results confirm our suspicion that band $A$ is the primary transcript of POMC. The size and the nuclear localization of band $\mathrm{B}$, taken together with its selective hybridization to the intron A probe, implicate

A)

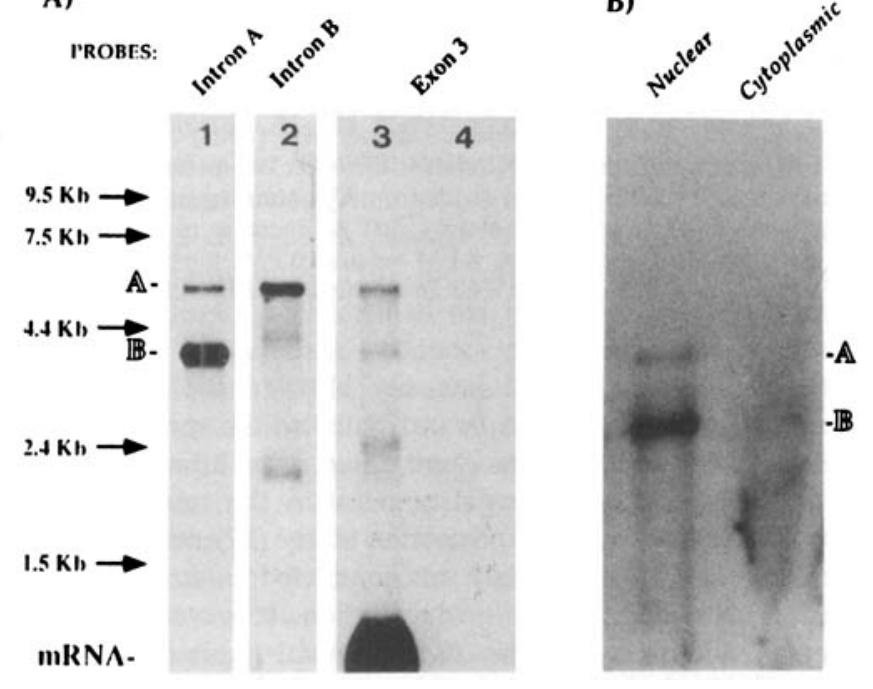

Fig. 2. (A) POMC RNA species characterized by successive probing of a poly-A RNA blot. Poly-A RNA from the anterior pituitary was used ( $5 \mu \mathrm{g} / \mathrm{lane}$ ). The membrane was probed successively by intron A (lane 1), intron B (lane 2), exon 1-2 (not shown), and exon 3 probes (lanes 3-4). The exposure time was $12 \mathrm{~h}$ at $-80^{\circ} \mathrm{C}$ for intron $\mathrm{A}, 36 \mathrm{~h}$ at $-80^{\circ} \mathrm{C}$ for intron $\mathrm{B}$ and exon 3 (band A-primary transcript; band B-putative intron A-containing intermediate). POMC MRNA was detected by the exonic probes. Hippocampal poly-A RNA $(5 \mu \mathrm{g})$ was loaded on lane 4 as control. Extraneous bands were periodically seen but were not consistently detected by all probes and thus were excluded from the primary transcript analysis. (B) Subcellular fractionation of anterior pituitary RNA. The nuclear fraction was pooled from three anterior pituitaries as described in Materials and Methods. Cytoplasmic RNA from the same preparation was loaded on the adjacent lane in proportion to the nuclear samples. The two bands, $\mathrm{A}$ and $\mathrm{B}$, were localized in the nuclear fraction after screening with an intron $A$ probe (exposure $-72 \mathrm{~h}$ at $-80^{\circ} \mathrm{C}$ ). this fragment as the intron A-containing processing intermediate. The relative abundance of the POMC RNA fragments was not analyzed in detail since large and small fragments may exhibit different transfer efficiencies, thus possibly underestimating the ratio of the primary transcript to processing intermediate, and similarly between nuclear to mature RNA species.

Changes in the primary transcript levels were determined under physiological conditions to ascertain the sensitivity of this assay. Blots constructed from total RNA of single anterior pituitaries were probed with the intron A-specific probe. The results are shown in Fig. 3. A single 30-min swim stress significantly increased plasma ACTH levels by $243 \%$ over unhandled controls (Student's $t$-test, $\mathrm{n}=6, \mathrm{P}<0.05$; Fig. 3 ). POMC primary transcript levels also increased at this time after normalizing to the amount of $18 \mathrm{~S}$ ribosomal RNA, with the group swum immediately before sacrifice exhibiting a $214 \%$ rise over the control group (Student's $t$-test, $\mathrm{n}=6, \mathrm{P}<0.01)$. Quantitation of the intron $\mathrm{A}$ intermediate species was not possible due to migration artefacts.

Finally, POMC hnRNA levels were measured during the circadian secretory period. Blots containing total RNA from single anterior pituitaries were probed by various cRNAs. The result of screening by an intron A probe is shown in Fig. 4. The amount of total RNA loaded on each lane was relatively consistent as seen by the levels of the $18 \mathrm{~S}$ ribosomal RNA observed after using a ribosomal-specific cDNA probe. One lane in the 10 PM group (denoted by a star) appeared to contain artefactual bands and was thus excluded from the quantitative analysis. The primary transcript (band A) and the putative processing intermediate (band B) levels were quantitated by optical densitometry, normalized to the amount of 18S ribosomal RNA, and expressed as percent of $4 \mathrm{PM}$ values. The primary transcript levels were different among the three time points (general ANOVA, $\mathrm{P}<0.005$; Fig. 5A), with $8 \mathrm{PM}$ values significantly increased over $4 \mathrm{PM}$ and $10 \mathrm{PM}$ levels $\left({ }^{* *} \mathrm{P}<0.05\right.$; Scheffe's F-test). Similarly, animals

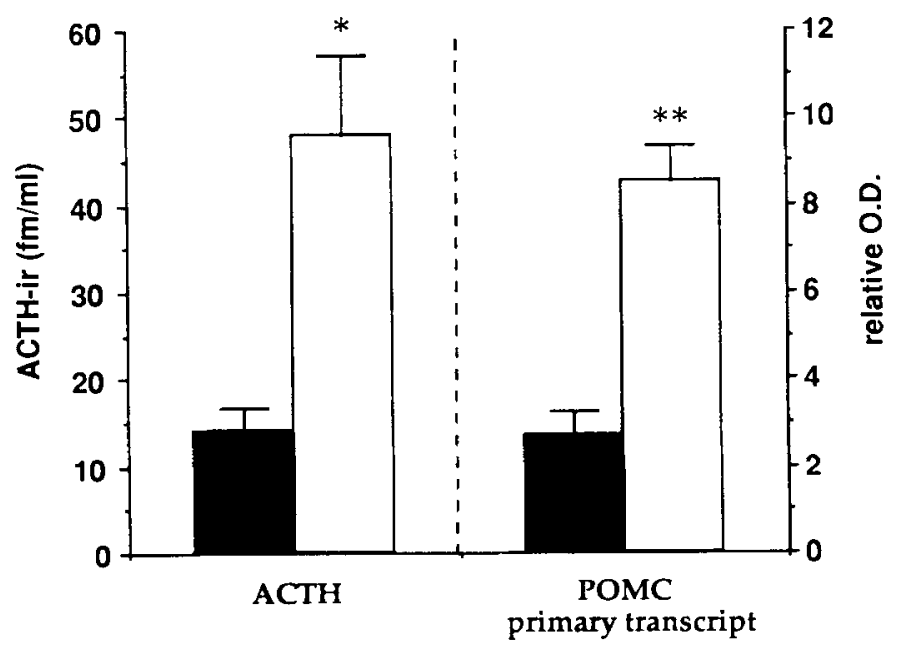

FIG. 3. The effects of swim stress on hnRNA levels and plasma ACTH. The levels of POMC primary transcript in the anterior pituitary and ACTH concentrations in plasma were measured from unhandled controls (dark bars) and animals swum for $30 \mathrm{~min}$ (open bars). Blots were probed with an intron A-specific cRNA. Optical density measurements of the primary transcript RNA were normalized to $18 \mathrm{~S}$ ribosomal signal and expressed as relative OD units. ACTH levels increased by $243 \%$ over resting levels ( ${ }^{*} \mathrm{P}<0.01, t$-test, $\left.\dot{\mathrm{n}}=6\right) ; \mathrm{hnRNA}$ increased over control values by $214 \%\left({ }^{* *} \mathrm{P}<0.001, t\right.$-test, $\mathrm{n}=6$ ). 


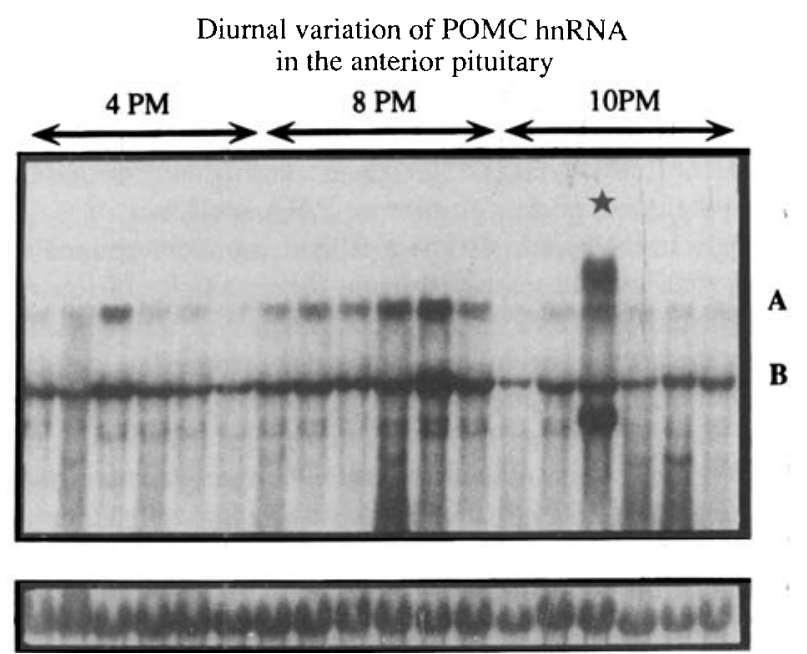

FIG. 4. Total RNA blot containing anterior pituitary samples from the diurnal study. The primary transcripts (band A) and the processing intermediates (band B) detected by the intron A-specific probe were quantified as described in Materials and Methods. One lane in the 10 PM group contained artefactual bands and was thus omitted from quantitation (star). The membrane was stripped, then subsequently probed with an exon 3 cRNA to quantify changes in mRNA levels. The total amount of RNA extracted from each anterior pituitary was generally consistent as determined by the intensity of the $18 \mathrm{~S}$ ribosomal signal in each lane after screening by a ribosomal cDNA (lower panel).

tested at 4 PM, 8 PM and 10 PM exhibited significant differences in their plasma ACTH levels ( ${ }^{*}$ Scheffe's F-test, $\mathrm{P}<0.05$; Fig. 5D), with the $8 \mathrm{PM}$ levels being increased $61 \%$ over $10 \mathrm{PM}$ levels. The levels of POMC processing intermediates and mRNA levels in the anterior pituitary (nuclear and cytoplasmic pooled) did not change (Fig. 5B and 5C, respectively). The median eminences of these animals were processed for $\mathrm{CRH}$ determination and expressed as percent of 4 PM levels. The average concentration of CRH immunoreactivity (ir) found at $4 \mathrm{PM}$ was $70 \pm 15 \mathrm{fmol} /$ median eminence. $\mathrm{CRH}$ peptide content did not vary across the three periods (Fig. 5E).

\section{Discussion}

The genomic sequence of rat POMC gene allows the prediction of various POMC RNA species which may exist in the cell. The sizes of RNA species detected by the intron A cRNA probe matched the predicted lengths of the primary hnRNA transcript and the intron A-containing processing intermediate. The emergence of band $\mathrm{A}$ after screening by intron $\mathrm{A}$, intron $\mathrm{B}$, exon 3 and exons $1-2$ probes strongly argues for it being the primary transcript of POMC. We conclude that band $\mathrm{B}$ represents the intron A-containing, intron B-spliced intermediate of POMC. The observation that the intron $B$ probe hybridizes to the $6.0 \mathrm{~kb}$ band but does not detect the $4.1 \mathrm{~kb}$ band supports this contention. Furthermore, bands $\mathrm{A}$ and $\mathrm{B}$ migrate in the nuclear fraction, indicating that these forms are nuclear transcripts of POMC.

The primary transcript and the intron A-containing intermediate levels have been previously determined by RNase protection assay and shown to be present in similar amounts in the anterior pituitary (17). In contrast, we often observed a stronger signal from the intron $\mathrm{A}$ intermediate species on our Northern
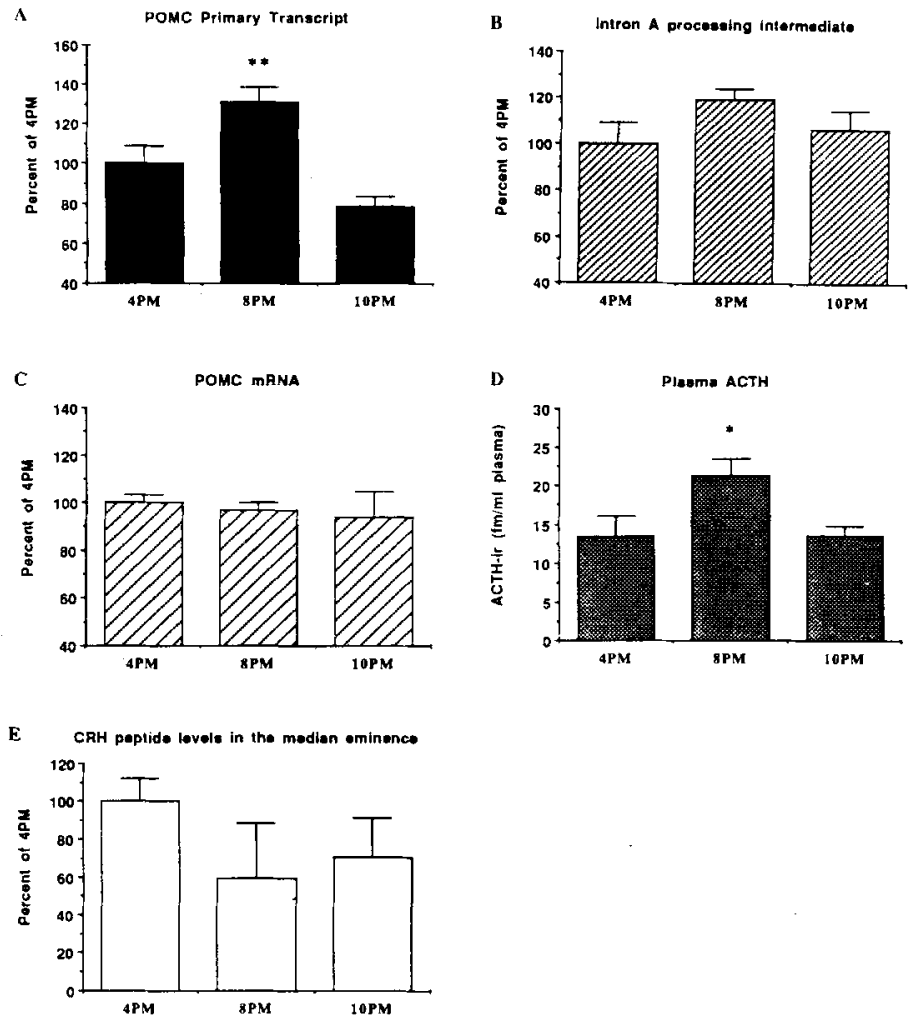

FIG. 5. Changes in various POMC measurements during the diurnal stimulatory period. Total RNA blots from animals sacrificed at the times indicated were processed. The primary transcript and the processing intermediate levels were quantified after screening with the intron $A$ probe. Variance in the amount of sample loaded in each lane was corrected by normalizing to the $18 \mathrm{~S}$ ribosomal signal. (A) Primary transcript levels at 8 PM were significantly elevated over the other two periods (** Scheffe's F-test, $n=6, P<0.05$ ). (B) and (C) Intron A-containing intermediate and mature mRNA levels did not change. (D) An increase in plasma ACTH was detected (*Scheffe's F-test, 8 PM versus $10 \mathrm{PM}, \mathrm{n}=6, \mathrm{P}<0.05$ ). (E) The content of $\mathrm{CRH}$-ir in the median eminence did not change.

blots. The unequal signal intensity between the primary and intermediate species cannot be attributed to the specificity of the probe, since similar results were often seen after probing by exonic cRNAs. The discrepancy between the results obtained from this and the RNase protection study (17) may arise from the fact that the RNase study was conducted in vitro on cultured pituitary cells 72 to $96 \mathrm{~h}$ after incubation. It is conceivable that this procedure may alter the transcriptional status of the POMC gene. Alternatively, it is possible that the present experiment yielded lower primary transcript levels than the intron A-containing intermediates since the larger RNA species may have transferred less efficiently on to the membrane. For the latter reason, we have limited our quantitative analysis to a comparison among identically sized bands without commenting on the abundance of the various POMC species. We have also noted the absence of the intron B-containing, intron A-spliced intermediate $(2.8 \mathrm{~kb}$ band) after probing the poly-A fraction with the intron $B$ probe (Fig. 2A). This observation is consistent with the previous study (17) and suggests that either intron B is consistently spliced out first, preventing the formation of an intron B-containing intermediate, or that such intermediates may be formed but rapidly converted to mature mRNA. 
We determined whether the sensitivity of the present assay was sufficient to detect changes in the primary transcript levels after HPA stimulation. The swim stress paradigm has been used previously by our laboratory $(21,22)$ and the effects on the pituitary have been well characterized. The most significant changes occur in the intermediate lobe. Profound upregulation has been documented in the contents of $\mathrm{N}$-acetyl $\beta$-endorphin after chronic treatment (21). The anterior pituitary in contrast is mildly affected. Chronic swim stress in our hands does not reliably alter the resting secretory status nor POMC biosynthesis. An acute treatment increases plasma ACTH during the first $5 \mathrm{~min}$ (22), followed by an increase in plasma levels of corticosterone. After $30 \mathrm{~min}$ of swim, plasma ACTH levels are essentially unchanged from those observed at $5 \mathrm{~min}$. In the present experiment, plasma ACTH levels increased approximately 2 -fold $(47 \mathrm{fm} /$ $\mathrm{ml}$ ) after $30 \mathrm{~min}$. Swim stress in the present study caused a significant $214 \%$ increase in primary transcript levels in the anterior pituitary. Detecting hnRNA changes of this magnitude therefore appears to be well within the sensitivity of this assay.

Changes in ACTH release appear to be tightly linked to transcription under various conditions (13-15). In earlier studies, transcriptional run-on assays have revealed decreases in transcription rate after dexamethasone or corticosterone injections at the earliest time assayed (15 min) (13). In the same study, a slight increase in transcription was observed $15 \mathrm{~min}$ after vehicle injection presumably in response to the stress associated with the injection. That these changes closely approximate the variation of plasma ACTH suggests that transcriptional changes are rapid and closely coupled to release. However, the relative effects on peptide release and gene transcription may depend on the type of stimulus. In a more recent study, Autelitano et al. (16) observed changes in plasma ACTH levels 30 min after exogenous CRH administration while transcription rates did not increase until 60 min post-treatment. Primary transcript levels and gene transcription rates changed in parallel despite the time lag between release and transcription (16), indicating that the transcriptional changes are rapidly reflected in the hnRNA levels. Our results suggest that swim stress produces a concomitant increase in plasma ACTH and POMC transcription within $30 \mathrm{~min}$.

Many mammals including rats and humans exhibit a diurnal steroid rhythm. In rats, peak levels are observed at the onset of the dark phase just as the animals become active (4). Since the rhythmic pattern of ACTH secretion, which generates the diurnal steroid fluctuation, distinguishes itself from the type observed during stress, we determined whether the diurnal drive is also capable of altering POMC hnRNA levels in the anterior pituitary. During other studies on CRH mRNA circadian rhythm, we have observed that under our housing conditions, rats exhibit the $\mathrm{ACTH}$ and the corticosterone peaks between $4 \mathrm{PM}$ and $8 \mathrm{PM}$ (unpublished observations). Consistent with these data, plasma ACTH levels in the present study were significantly different between 4 PM, 8 PM and 10 PM. High ACTH levels were found at $8 \mathrm{PM}$ but not at $10 \mathrm{PM}$, indicating that the diurnal elevation occurred near the onset of dark (between 4 PM and 8 PM) but returned to baseline levels by $10 \mathrm{PM}$. The changes in primary hnRNA transcript levels closely paralleled those of plasma ACTH, suggesting that diurnal drive increased both release and transcription. The decrease in ACTH levels at $10 \mathrm{PM}$ may result as a consequence of steroid feedback, since corticosterone levels are known to peak around this time.
Despite the significant increases in POMC primary transcript and plasma ACTH levels, POMC mRNA levels remained unchanged among the three periods. These observations are in good agreement with our previous results (20). It appears that the transient increases in transcription caused by the diurnal drive do not affect the stable (and sizeable) mRNA pool. Levels of intron A-containing intermediates tended to increase at $8 \mathrm{PM}$ but did not reach statistical significance. Interestingly, the finding that the processing intermediate levels appear to be more resistant to change is consistent with the results obtained by RNase protection (17). Further studies are necessary to determine whether the difference in the rate of accumulation of primary and intermediate species may be due to their respective turnover rates.

CRH has been proposed to be involved in the diurnal rhythm of the HPA axis. Several studies have reported that the $\mathrm{CRH}$ peptide content fluctuates diurnally in the hypothalamus (23-25). $\mathrm{CRH}$ levels in the median eminence during the evening have been shown to be inversely related to the amount of ACTH found in plasma. Furthermore, we have observed that CRH mRNA levels fluctuate diurnally as well, with the peak occurring a few hours prior to the dark phase and followed by a sharp decrease a few hours afterwards (20). The present results, which indicate that the relative levels of $\mathrm{CRH}$-ir in the median eminence tended to decrease as plasma ACTH levels increased, are consistent with previous observations. In vitro data also indicate that $\mathrm{CRH}$ but not AVP can acutely increase POMC hnRNA levels (17). These findings taken together lend support to the idea that diurnal $\mathrm{CRH}$ release stimulates POMC transcription as well as ACTH secretion from the anterior pituitary. We speculate that CRH and glucocorticoid feedback operate as opposing forces to regulate POMC expression during the circadian rhythm in a manner akin to their regulation of stress responses.

\section{Materials and Methods}

Male Sprague-Dawley rats (Charles River, Portage) weighing 250 to $275 \mathrm{~g}$ were used throughout the studies. Animals were caged six per group and were given food and water ad libitum. A $12 \mathrm{~h}$ light-dark cycle was set at $6 \mathrm{AM}$ lights-on, 6 PM lights-off. The effects of acute swim stress on POMC hnRNA levels were initially determined. Rats $(n=6)$ were swum in a water-tank $\left(32^{\circ} \mathrm{C}\right)$ for $30 \mathrm{~min}$ and sacrificed immediately afterwards. Naive unhandled animals served as controls. For the diurnal study, levels of POMC hnRNA in the anterior pituitary were determined during the evening when the endogenous secretion is known to occur. Rats $(n=5-6)$ were acclimated to the environment described above for 10 days prior to the experiment. Animals were sacrificed at $4 \mathrm{PM}, 8 \mathrm{PM}$ and $10 \mathrm{PM}$.

Animals were rapidly decapitated and their brains removed. Trunk blood was collected for plasma ACTH determination. Anterior pituitary tissues were extracted for total $\mathrm{RNA}$ using a $\mathrm{LiCl}$ precipitation method (26) modified as follows: Tissues were homogenized through a 26 gauge needle in 300 to $500 \mu 1$ of GT buffer ( $5 \mathrm{M}$ guanidinium isothiocyanate, $10 \mathrm{mM}$ EDTA (pH 8.0), $50 \mathrm{mM}$ Tris pH 7.5, 8\% mercaptoethanol). Five volumes of $\mathrm{LiCl}(4 \mathrm{M})$ were added and the samples were precipitated at $4{ }^{\circ} \mathrm{C}$ overnight. Tubes were centrifuged at $10,000 \times \mathrm{g}$ for $15 \mathrm{~min}$ to collect the pellet, then resuspended in $300 \mu \mathrm{l}$ of proteinase $\mathrm{K}$ buffer $(150 \mu \mathrm{g} / \mathrm{ml}$ proteinase K; Boehringer Mannheim). Tubes were incubated at $42{ }^{\circ} \mathrm{C}$ for 1 to $2 \mathrm{~h}$, phenol/chloroform extracted once, then precipitated in EtOH. The nuclear fractions of the anterior pituitary tissues were also obtained in a separate study to localize the putative hnPOMC RNA. Three anterior pituitary tissues were pooled and processed as described in Blum (27) with the exception of an extra DNase I treatment (DNase RQ1, Promega) immediately prior to loading on the formaldehyde-agarose gel. 


\section{Northern gel analysis}

A I $\%$ agarose formaldehyde gel was prepared in $1 \times$ Hepes buffer $(20 \mathrm{mM}$ Hepes, $1 \mathrm{mM}$ EDTA, 6\% formaldehyde). Total RNA from single pituitary samples were loaded on a horizontal gel and electrophoresed overnight, washed in water for $1 \mathrm{~h}$, then blotted on Nytran $(0.45 \mu \mathrm{m}$; Schleicher and Schuell) overnight. A half to a whole anterior pituitary sample was required for detection of the primary transcripts. Air-dried membranes were briefly crosslinked by UV light $(350 \mathrm{~nm}$ for $20 \mathrm{~s})$.

\section{Probe synthesis and hybridization}

Genomic fragments of POMC intron A, intron B and exon 3 were generous gifts from Dr J. Roberts (Mt. Sinai, NY, USA). Riboprobes for intron A were generated from a genomic fragment described by Fremeau et al. (28). The intron B-specific probe was a $300 \mathrm{nt}$ antisense transcript of the AccI-Xbal fragment $\sim 100$ nts downstream of exon 2 (see Fig. 1). The 350 nt exon 3 probe was prepared as previously described (28). A probe spanning exons 1 and 2 which would complement the exon 3 cDNA in screening the entire mRNA sequence was cloned from the rat anterior pituitary cDNA by PCR (29). The sense oligonucleotide for the $5^{\prime}$ end of the mRNA corresponded to the sequence $66 \mathrm{nts}$ downstream of the cap site (i.e. within intron 1 ); the $3^{\prime}$ end oligonucleotide corresponded to the middle region of exon 2 (spanning amino-acid $1-7$ of the $16 \mathrm{~K}$ protein). Amplification proceeded as described (30) for 30 cycles using a 2 -step parameter $\left(94^{\circ}\right.$ to $\left.63^{\circ} \mathrm{C}\right)$. The clone obtained by this procedure was $150 \mathrm{nts}$ long spanning exon $\perp$ and 2 and was an exon 2-extended form of the POMC mRNA (see Fig. 1). Probes were labeled to high specific activity using [ $\left.{ }^{32} \mathrm{P}\right] \mathrm{UTP}(25 \mu \mathrm{l}$ of $>3,000 \mathrm{Ci} / \mathrm{mmol}$;CN, Irvine, USA) and hybridized in $50 \%$ formamide, $\mathrm{NaPO}_{4}(400 \mathrm{mM}), \mathrm{SDS}$ $(5 \%)$ buffer containing bovine serum albumin (BSA) $(1 \mathrm{mg} / \mathrm{ml}$; Sigma, St. Louis, MO, USA) at $60^{\circ} \mathrm{C}$ overnight. Membranes were rinsed, then washed at $70^{\circ} \mathrm{C}$ in $0.1 \times \mathrm{SSC}$ for $2 \mathrm{~h}$, and finally exposed on film for 1 to 3 days at $-80^{\circ} \mathrm{C}$. Membranes were stored desiccated for 2 to 3 weeks and always boiled in $\mathrm{H}_{2} \mathrm{O}$ for $15 \mathrm{~min}$ before reprobing. The hnRNA bands on the film were quantitated by optical densitometry (Loats Associates). Results from the physiological studies were always normalized to the amount of $18 \mathrm{~S}$ ribosomal RNA.

\section{Plasma ACTH RIA}

ACTH was assayed by RIA as previously described (21) using an antibody raised in rabbits against synthetic ACTH $(11-24)$. This midportion antibody recognizes full ACTH $(1-39)$ but has little cross-reactivity $(<5 \%)$ to $\alpha$-melanocyte-stimulating hormone and ACTH (18-39). Triplicate samples were diluted in $0.1 \%$ human serum albumin (Sigma) and adjusted to $\mathrm{pH} 3.0$ by $1 \mathrm{~N} \mathrm{HCl}$. The RIA buffer $(0.1 \mathrm{M} \mathrm{NaCl}, 0.0004 \mathrm{M}$ EDTA, $0.02 \%$ sodium azide, $0.1 \%$ polylysine at $\mathrm{pH} 7.6$ ) was added and the antiserum was used at the final dilution of $1: 80,000$. The radioligand used was [ ${ }^{125}$ I]ACTH $(1-39)$.

\section{CRH RIA of the median eminence}

The rat $\mathrm{CRH}$ antibody (a generous gift from Dr $\mathrm{H}$. Vaudry) was used at the titer of $1 / 10,000$. This antibody reacts mainly with the 22-39 residue of synthetic $\mathrm{CRH}_{1-41}$ (31). The median eminence was dissected from the ventral surface of the hypothalamus. Tissues were extracted in a $0.2 \mathrm{~N} \mathrm{HCl}$-acetone mix $(1: 3)$, homogenized by a polytron for $1 \mathrm{~min}$, and the supernatant was lyophilized. Extracted samples were diluted in CRH RIA buffer ( $50 \mathrm{mM} \mathrm{NaPO}, 50 \mathrm{mM} \mathrm{NaCl}, 0.5 \%$ BSA), then a twentieth fraction of the sample was used per tube. Duplicate samples were processed under disequilibrium conditions with $\left[{ }^{125} \mathrm{I}\right] \mathrm{CRH}$ (ovine) used as trace. The relative levels of $\mathrm{CRH}$-ir in the median eminence obtained by this assay were expressed as percent of 4 PM values.

Results were statistically analyzed by Student's t-test or ANOVA followed by Scheffe's F-test whenever appropriate. A confidence level above $95 \%$ was considered significant.

\section{Acknowledgements}

The authors thank Dr J. L. Roberts for generously supplying us with the POMC genomic clones. We also wish to thank Dr H. Vaudry for the $\mathrm{CRH}$ antibody and Dr R. C. Thompson for the critical evaluation of the manuscript. This work was supported by NIMH grant MH42251 and NIDA grant DA02265 (awarded to S.J.W.).

Accepted 28 August 1991

\section{References}

1. Dallman MF, Akana SF, Cascio CS, Darlington DN, Jacobson L, Levin N. (1987). Regulation of ACTH secretion: variations on a theme of B. Recent Prog Horm Res. 43: 113-173.

2. Sato T, Sato M, Shinsako J, Dallman MF. (1975). Corticosteroneinduced changes in hypothalamic corticotropin-releasing factor (CRF) content after stress. Endocrinology. 97: 265-274.

3. Murakami K, Akana S, Dallman MF, Ganong WF. (1989). Correlation between the stress-induced transient increase in corticotropinreleasing hormone content of the median eminence of the hypothalamus and adrenocorticotropic hormone secretion. Neuroendocrinology. 49: 233-241.

4. Krieger DT. (1975). Circadian pituitary adrenal rhythms. Adv Exp Med Biol. 54: 169-189.

5. Krieger DT. (1977). Regulation of circadian periodicity of plasma ACTH levels. Ann NY Acad Sci. 297: 561-567.

6. Keller-Wood ME, Dallman MF. (1984). Corticosteroid inhibition of ACTH secretion. Endocr Rev. 5: 1-24.

7. Widmaier EP, Dallman MF. (1984). The effects of corticotropinreleasing factor on adrenocorticotropin secretion from perifused pituitaries in vitro: rapid inhibition by glucocorticoids. Endocrinology. 115: $2368-2374$.

8. Buckingham JC. (1979). The influence of corticosteroids on the secretion of corticotropin and its hypothalamic releasing hormone. J Physiol (Lond). 286: 331-342.

9. Herman JP, Shafer MK-H, Young EA, Thompson RC, Douglas JO, Akil H, Watson SJ. (1989). Evidence for hippocampal regulation of neuroendocrine neurons of the hypothalamo-pituitary-adrenocortical axis. J Neurosci. 9: 3072-3082.

10. Levin N, Shinsako J, Dallman MF. (1988). Corticosterone acts on the brain to inhibit adrenalectomy-induced adrenocorticotropin secretion. Endocrinology. 122: 694-701.

11. Kovacs K, Kiss JZ, Makara GB. (1986). Glucocorticoid implants around the hypothalamic paraventricular nucleus prevent the increase of corticotropin-releasing factor and arginine vasopressin immunostaining induced by adrenalectomy. Neuroendocrinology. 44: 229-234.

12. Sawchenko PE. (1987). Evidence for a local site of action for glucocorticoids in inhibiting CRF and vasopressin expression in the paraventricular nucleus. Brain Res. 403: 213-224.

13. Eberwine JH, Roberts JL. (1984). Glucocorticoid regulation of proopiomelanocortin gene transcription in the rat pituitary. J Biol Chem. 259: $2166-2170$.

14. Birnberg NC, Lissitzky J-C, Minman M, Herbert E. (1983). Glucocorticoids regulate proopiomelanocortin gene expression in vivo at the levels of transcription and secretion. Proc Natl Acad Sci USA. 80: $6982-6986$.

15. Gagner JP, Drouin J. (1985). Opposite regulation of proopiomelanocortin gene transcription by glucocorticoids and CRH. Mol Cell Endocrinol. 40: 25-32.

16. Autelitano DJ, Blum M, Lopinco M, Allen RG, Roberts JL. (1990). Corticotropin-releasing factor differentially regulates anterior and intermediate pituitary lobe proopiomelanocortin gene transcription, nuclear precursor RNA and mature mRNA in vivo. Neuroendocrinology. 51: $123-130$.

17. Levin N, Blum M, Roberts JL. (1989). Modulation of basal and corticotropin-releasing factor-stimulated proopiomelanocortin gene expression by vasopressin in rat anterior pituitary. Endocrinology. 125: $2957-2966$

18. Drouin J, Chamberland M, Charron J, Jeannotte L, Nemer M. (1985). Structure of the rat proopiomelanocortin (POMC) gene. FEBS Lett. 193: 54-58.

19. Carnes M, Lent SJ, Goodman B, Mueller C, Saydoff J, Erisman S. (1990). Effects of immunoneutralization of corticotropin-releasing hormone on ultradian rhythms of plasma adrenocorticotropin. Endocrinology. 126: 1904-1913.

20. Kwak SP, Young EA, Akil H, Watson SJ. (1989). Circadian variation 
of neuropeptide mRNA in the paraventricular nucleus and pituitary. Soc Neurosci Abstr. 800: Abstr. 321.3.

21. Young EA. (1990). Induction of the intermediate lobe pro-opiomelanocortin system with chronic swim stress and $\beta$-adrenergic modulation of this induction. Neuroendocrinology. 52: 405-414.

22. Young EA, Akana S, Daliman MF. (1990). Decreased sensitivity to glucocorticoid fast feedback in chronically stressed rats. Neuroendocrinology. 51: $536-542$.

23. Owens MJ, Bartolome J, Schanberg SM, Nemeroff CB. (1990). Corticotropin-releasing factor concentrations exhibit an apparent diurnal rhythm in hypothalamic and extrahypothalamic brain regions: differential sensitivity to corticosterone. Neuroendocrinology. 52: 626-631.

24. Fishman AJ, Kastin AJ, Graf MV, Moldow RL. (1988). Constant light and dark affect the circadian rhythm of the hypothalamicpituitary-adrenal axis. Neuroendocrinology. 47: 309-316.

25. Szafarczyk A, Hery M, Laplante E, Jxart G, Assenmacher I. Kordon C. (1980). Temporal relationships between the circadian rhythmicity in plasma levels of pituitary hormones and in hypothalamic concentrations of releasing factors. Neuroendocrinology. 30: 369-376.
26. Cathala G, Savouret JF, Mendez B, West BL, Karin M, Martial JA, Baxter JD. (1983). A method for isolation of intact, translationally active ribonucleic acid. DNA. 2: $329-335$

27. Blum M. (1989). Regulation of neuroendocrine peptide gene expression. Methods Enzymol. 168: 318-333.

28. Fremeau RT, Lundblad JR, Pritchett DB, Wilcox IN, Roberts JL. (1986). Regulation of proopiomelanocortin gene transcription in individual cell nuclei. Science. 234: 1265-1269.

29. Sarkar G, Sommer SS. (1989). Access to a messenger RNA sequence or its protein product is not limited by tissue or species specificity. Science. 244: $331-334$.

30. Saiki RK, Gelfand DH, Stoffel S, Scharf SJ, Higuchi R, Horn GT, Mullis KB, Erlich HA. (1988). Primer-directed enzymatic amplification of DNA with a thermostable DNA polymerase. Science. 239: 487-491.

31. Burlet A, Tonon M-C, Tankosic P, Coy D, Vaudry H. (1983). Comparative immunocytochemical localization of corticotropin releasing factor (CRF-41) and neurohypophysial peptides in the brain of Brattleboro and Long-Evans rats. Neuroendocrinology. 37: $64-72$. 